\title{
Corrigendum to "Microbial Food Safety Risk to Humans Associated with Poultry Feed: The Role of Irradiation"
}

\author{
Tahiru Mahami $\mathbb{D}$, Wellington Torgby-Tetteh, Delali Isaac Kottoh, \\ Leticia Amoakoah Twum, Emmanuel Gasu, Sylvester Nana Yao Annan, \\ Daniel Larbi, Isaac Adjei, and Abraham Adu-Gyamfi
}

\author{
Biotechnology and Nuclear Agriculture Research Institute (BNARI), Ghana Atomic Energy Commission, P. O. Box LG 80, \\ Legon, Accra, Ghana \\ Correspondence should be addressed to Tahiru Mahami; tmahami@yahoo.com \\ Received 17 March 2019; Accepted 20 March 2019; Published 2 May 2019 \\ Copyright (C) 2019 Tahiru Mahami et al. This is an open access article distributed under the Creative Commons Attribution License, \\ which permits unrestricted use, distribution, and reproduction in any medium, provided the original work is properly cited.
}

In the article titled "Microbial Food Safety Risk to Humans Associated with Poultry Feed: The Role of Irradiation" [1], the name of the second author was given incorrectly as Wellington Togby-Tetteh. The author's name should have been written as Wellington Torgby-Tetteh. The revised authors' list is shown above.

\section{References}

[1] T. Mahami, W. Togby-Tetteh, D. I. Kottoh et al., "Microbial Food Safety Risk to Humans Associated with Poultry Feed: The Role of Irradiation," International Journal of Food Science, vol. 2019, Article ID 6915736, 7 pages, 2019. 


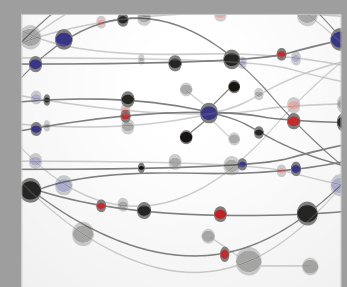

The Scientific World Journal
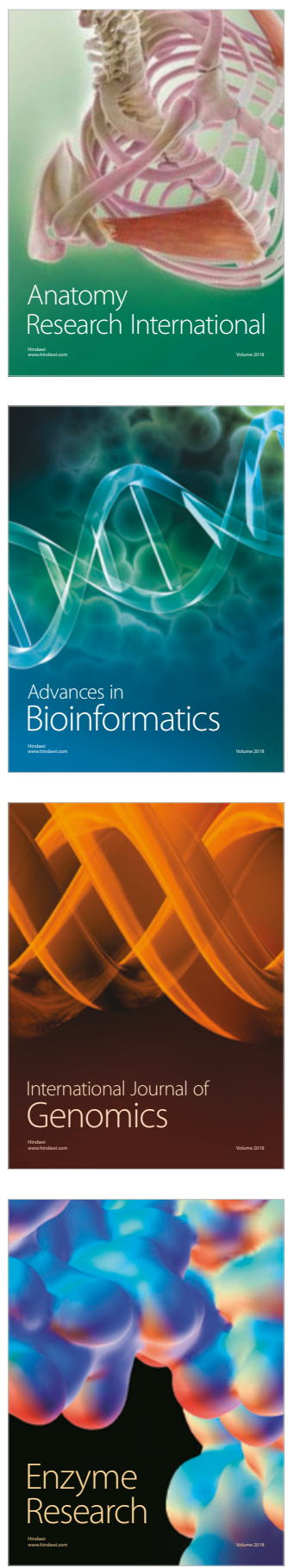
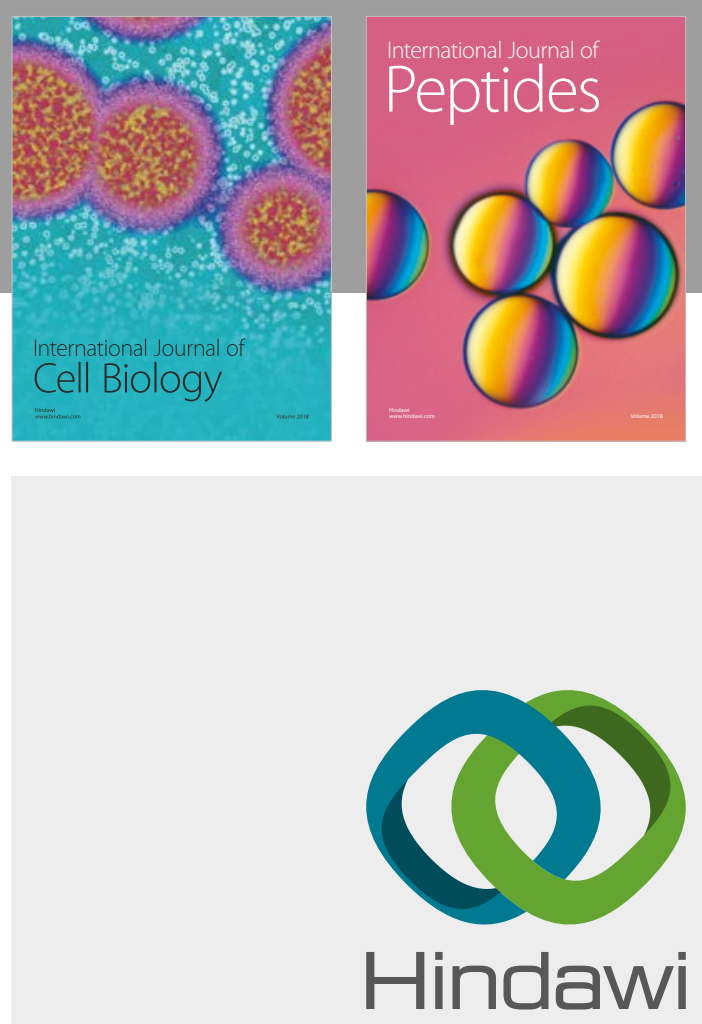

Submit your manuscripts at

www.hindawi.com
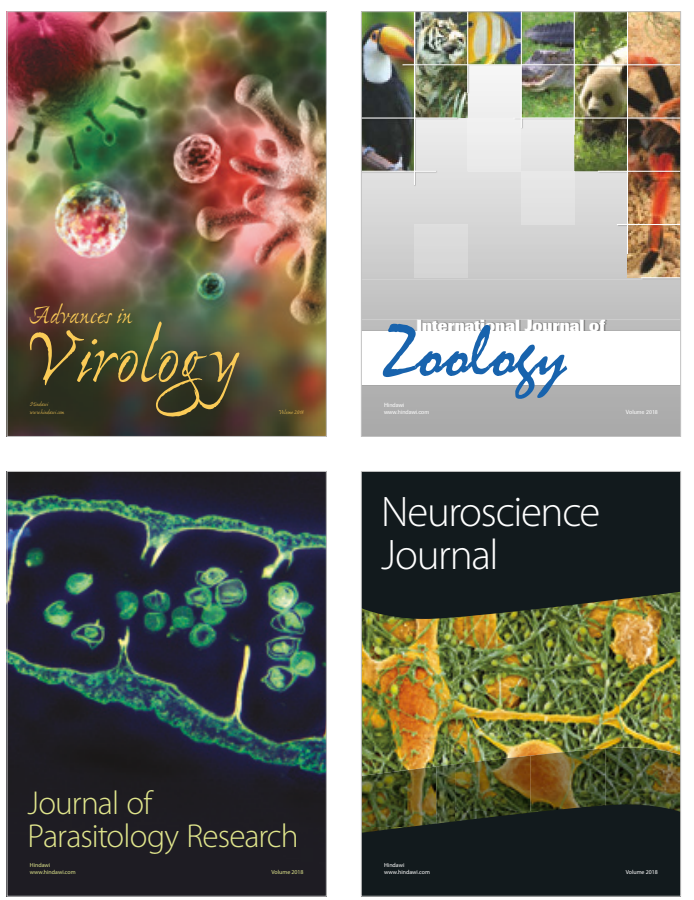
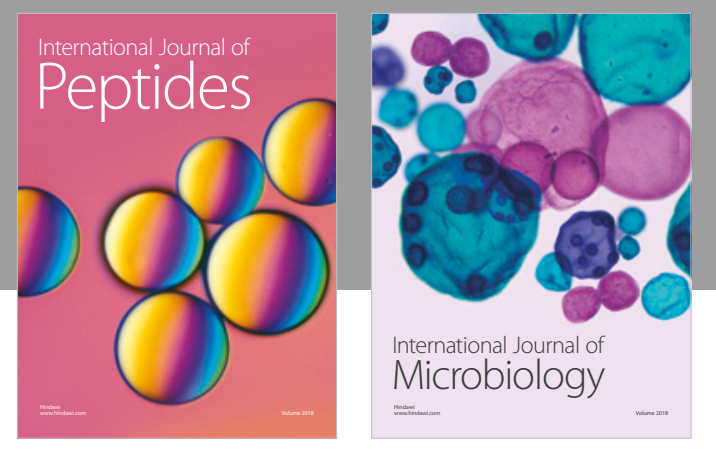

nternational Journal of Microbiology
Journal of
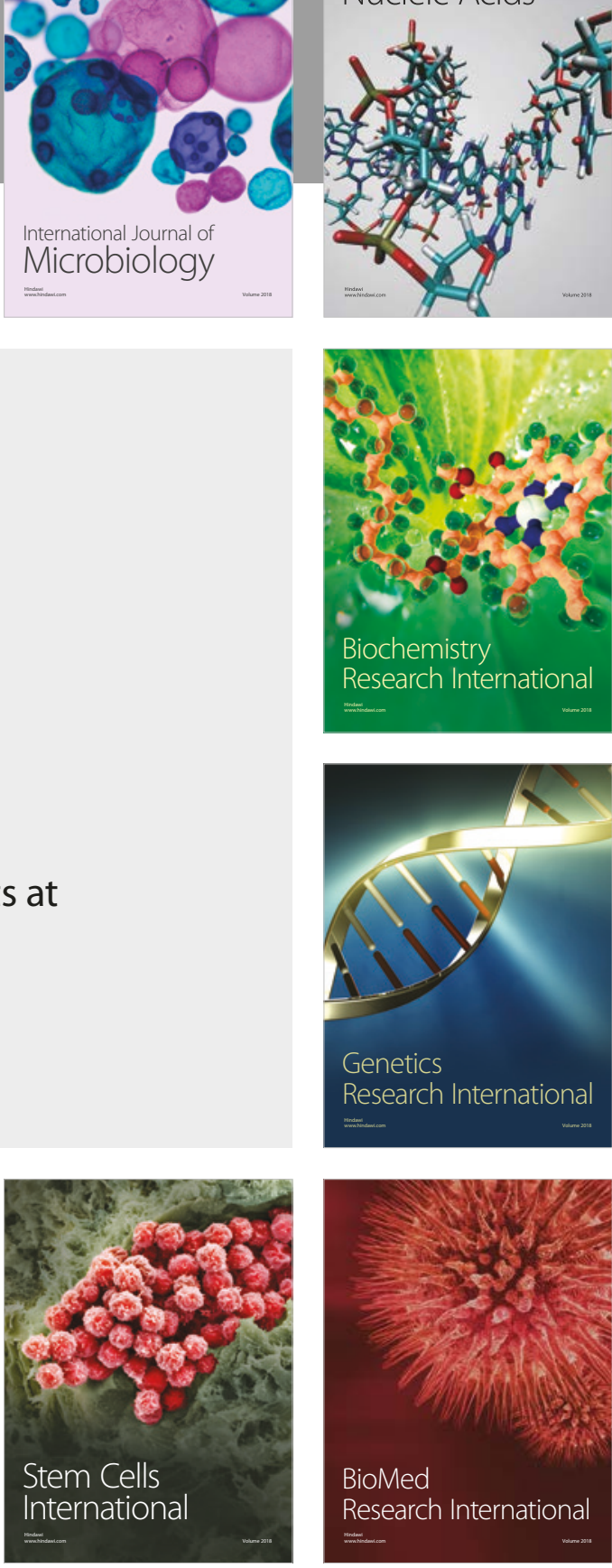
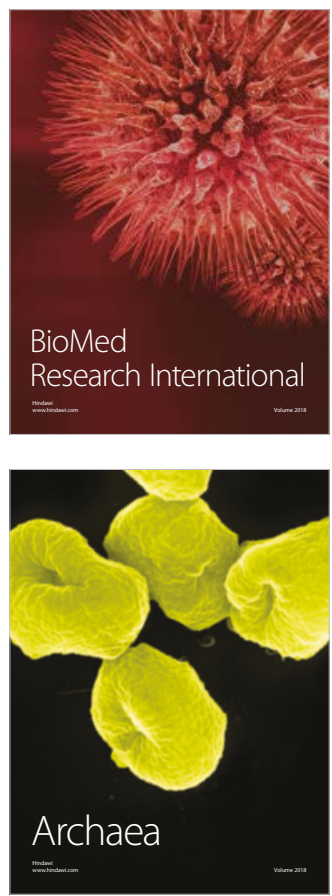